\title{
A INTEGRALIDADE NOS CENTROS DE ESPECIALIDADES ODONTOLÓGICAS.
}

THE INTEGRALITY IN THE CENTERS OF DENTAL SPECIALITIES.

Sérgio Spezzia*

* Cirurgião Dentista. Especialista em Gestão em Saúde pela Universidade Federal de São Paulo. Mestre em Ciências pela Escola Paulista de Medicina - Universidade Federal de São Paulo.

sergio.spezzia@unifesp.br

Categoria: Revisão de Literatura 


\section{Resumo}

O Sistema Único de Saúde (SUS) é o responsável pelos atendimentos de saúde públicos realizados à população. O funcionamento do SUS fundamenta-se em diretrizes organizativas: Universalidade, Integralidade e Equidade e em princípios doutrinários: Descentralização, Regionalização, Hierarquização, Participação Comunitária e Integração. $\mathrm{O}$ atendimento assistencial em âmbito odontológico ocorre a nível de atenção primária, secundária e terciária. $\mathrm{Na}$ atenção secundária ou de média complexidade os Centros de Especialidades Odontológicas, detém papel de destaque no contexto da integralidade. A integralidade é considerada por muitos como diretriz, princípio, objetivo, política, estratégia, ideal, bandeira de luta ou como ação social de interação democrática entre sujeitos no que tange ao cuidado em qualquer nível dos serviços de saúde. Sob o ponto de vista do SUS, a integralidade em saúde tem como parte inerente, essencialmente, a assistência odontológica, já que toda a população basicamente tem histórico de estar acometida ou de ter estado acometida por algum tipo de doença bucal. O CEO visa propiciar a integralidade nos atendimentos prestados à população. O objetivo deste artigo foi averiguar como procede a prática da integralidade nos CEO. Atualmente ainda, a integralidade tem pouca visibilidade nas práticas de saúde. Existe avanços, no entanto, que ainda não alcançaram o patamar desejado. Concluiu-se que a prática da integralidade nos CEO tende a aprimorar os atendimentos, permitindo racionalização dos recursos, evitando maiores gastos na atenção em saúde.

Palavras-Chave: Integralidade em Saúde. Atenção Secundária à Saúde. Recursos Humanos em Odontologia.

Key-words: Integrality in Health. Secondary Care. Dental Staff.

\section{Introdução}


O Sistema Único de Saúde (SUS) é o responsável pelos atendimentos de saúde públicos realizados à população. O funcionamento do SUS fundamenta-se em diretrizes organizativas: Universalidade, Integralidade e Equidade e em princípios doutrinários: Descentralização, Regionalização, Hierarquização, Participação Comunitária e Integração.

A Política Nacional de Saúde Bucal (PNSB), intitulada Programa Brasil Sorridente (PBS), foi instituída em 2004, no intuito de assegurar ações de promoção, prevenção e recuperação da saúde bucal da população, preconizando atendimentos odontológicos nos níveis de atenção secundário e terciário, bem como adotando o princípio da integralidade na promoção dos serviços de saúde bucal. Buscou-se melhoria na organização dos sistemas de saúde, tomando por base a adoção de um modelo que suprisse os princípios do SUS de universalidade, equidade e integralidade. Nesse programa a oferta da atenção secundária seria viabilizada pelos Centros de Especialidades Odontológicas (CEO) (Ministério da Saúde. Coordenação Nacional de Saúde, 2004).

O objetivo deste artigo foi averiguar como procede a prática da integralidade nos CEO.

\section{Revisão de Literatura}

$\mathrm{Na}$ integralidade trata-se a pessoa como ser humano com mais cuidado e mais delicadeza, levando em consideração acima de tudo suas necessidades, abrangendo, portanto, cuidar do todo. Em se tratando do cuidado empreendido para pessoas, grupos e coletividades, a integralidade considera o usuário como um sujeito histórico, social e político, integrado ao seu habitat familiar, ao meio ambiente, bem como a sociedade da qual faz parte. Nela identifica-se os sujeitos como totalidades, levando-se em consideração todas dimensões existentes com acesso possibilitado pelos próprios sujeitos (Viegas \& Penna, 2015).

A integralidade é considerada por muitos como diretriz, princípio, objetivo, 
política, estratégia, ideal, bandeira de luta ou como ação social de interação democrática entre sujeitos no que tange ao cuidado em qualquer nível dos serviços de saúde. Sob o enfoque da perspectiva dos usuários, a ação integral está associada ao tratamento digno, respeitoso, com qualidade, vínculo e acolhimento (Mattos, 2001; Campos, 2003).

$\mathrm{Na}$ integralidade ter-se-à assistência em todos níveis de atenção, além disso ela será fruto da relação desse princípio assistencial com a ideia de um todo, de assistência integral ao usuário como ser humano, que precisa de assistência humanizada e de acolhimento adequado, com tratamento digno e com vínculo, levando em conta o meio em que ele mora, suas redes sociais, apoiadas no auxílio familiar, sem perder o foco centrado no ser humano (Freitas et al., 2014).

Num modelo de saúde considerado integral deve-se ter suficiência de meios para cobrir ações de saúde inespecíficas voltadas para promoção de saúde em grupos populacionais definidos e para suprir ações de saúde específicas, destinadas a vigilância ambiental, sanitária e epidemiológica, no intuito de controlar riscos e danos. Além disso, deve haver ações para detecção precoce de doenças, englobando ações de diagnóstico, tratamento e reabilitação. Para que ocorra resolutividade em saúde, a integralidade tem papel central no modelo de saúde proposto para que se obtenha universalidade e equidade mais efetivamente (Mattos, 2004; Sala et al., 2011; Freitas et al., 2014).

$\mathrm{Na}$ literatura científica, a integralidade figura como termo plural, ético e democrático, que é possuidor de diferentes sentidos e usos. Para a integralidade devemos repensar a organização do processo de trabalho, de gestão e de planejamento com o emprego da construção de saberes e de práticas de saúde estruturadas (Fracolli et al., 2011).

Sob o ponto de vista do SUS, a integralidade em saúde tem como parte inerente, essencialmente, a assistência odontológica, já que toda a população basicamente tem histórico de estar acometida ou de ter estado acometida por algum tipo de doença bucal. Nesse contexto, cárie dental e doença periodontal figuram como as mais prevalentes (Ministério da Saúde, SB Brasil, 2011; Wade, 2013).

No contexto da PNSB e dos princípios norteadores propostos, as ações de saúde 
bucal com maior grau de complexidade, portanto, deveriam ser encaminhadas aos CEO. Os CEO são estabelecimentos de saúde com registro no Cadastro Nacional de Estabelecimentos de Saúde (CNES) e que são classificados como sendo uma Clínica Especializada ou um Ambulatório de Especialidades (Brasil, 2006).

Os CEO são classificados em tipo 1 e 2, em conformidade com os requisitos descritos no anexo I da Portaria GM 1570, de 29 de julho de 2004, publicada em 15/09/04. No tipo 1, têm-se centro de especialidades odontológicas com 3 ou mais cirurgiões dentistas, que no total abrangem 120 horas semanais de atendimento e 1 auxiliar de consultório dentário para cada cirurgião dentista, contando ainda com um pessoal mínimo na parte administrativa com recepcionista, auxiliar de serviços gerais e auxiliar administrativo. No tipo 2, têm-se 4 ou mais cirurgiões dentistas, que no total abrangem 160 horas semanais de atendimentos; 1 auxiliar de consultório para cada dentista e pessoal para a parte administrativa, incluindo recepcionista, auxiliar de serviços gerais e auxiliar administrativo.

Em conformidade com o número de cadeiras odontológicas presentes, os CEO podem ser de tipo I, II ou III. No tipo I existe 3 cadeiras odontológicas, no tipo II, têm-se número de 4 a 6 cadeiras odontológicas e no tipo III, têm-se 7 ou mais cadeiras odontológicas (Portaria 1570, 2004).

Os CEO agem complementarmente as ações preconizadas pela Atenção Básica. Possuem serviços especializados em diagnóstico bucal com ênfase no diagnóstico do câncer bucal, empreendo procedimentos que abrangem periodontia especializada, cirurgia oral menor dos tecidos moles e duros, endodontia e atendimento a pessoas com necessidades especiais. A meta mensal por subgrupo para cada tipo de CEO foi firmada pelas Portarias no. 600/GM de 2006 e 1464/GM de 2011: CEO tipo I - 80 procedimentos do subgrupo básico; 60 procedimentos do subgrupo periodontia; 35 procedimentos do subgrupo endodontia; e 80 procedimentos do subgrupo cirurgia oral menor; CEO tipo II - 110 procedimentos do subgrupo básico; 90 procedimentos do subgrupo periodontia; 60 procedimentos do subgrupo endodontia; e 90 procedimentos do subgrupo cirurgia oral menor e CEO tipo III - 190 procedimentos do subgrupo básico; 150 procedimentos do subgrupo periodontia; 95 procedimentos do subgrupo 
endodontia; e 170 procedimentos do subgrupo cirurgia oral menor.

Esses serviços somente terão a meta atingida considerada quando cumprirem percentual igual ou maior que $100 \%$ da meta normatizada para cada subgrupo. Em seguida os CEO serão classificados em: desempenho péssimo (CEO que não cumpriu nenhuma meta); desempenho ruim (CEO que cumpriu apenas 1 meta); desempenho regular (CEO que cumpriu 2 metas); desempenho bom (CEO que cumpriu 3 metas) e desempenho ótimo (CEO que cumpriu a totalidade das metas) (Portaria 1570, 2004). O CEO visa propiciar a integralidade nos atendimentos prestados à população e para tanto deve cumprir com essas metas em sua totalidade (Chaves et al., 2010; Lima et al., 2010).

A prática da integralidade tende a proporcionar efetividade na assistência à saúde bucal prestada, possibilitando uma relação harmoniosa entre pacientes, cirurgiões dentistas e gestores com melhora na qualidade dos serviços prestados (Silva Jr. \& Mascarenhas, 2004; Pinheiro \& Mattos, 2006).

\section{Discussão}

Muitos estudos tem a integralidade definida como sendo sinônimo de garantia de acesso a todos níveis existentes do sistema de saúde (Mattos, 2004).

O acolhimento faz parte da integralidade da atenção em saúde, no entanto, esse conceito acha-se ainda em processo de construção (Brasil, 2013).

A proposta do PBS, nesse contexto, visava mudar o perfil da atenção a saúde bucal, almejando propiciar atendimento integral, acolhedor e humanizador.

Os CEO tendem a apresentar seus atendimentos com a integralidade em fase de estruturação, principalmente no que tange ao aprimoramento dos processos de acolhimento e humanização.

É imprescindível que o emprego da integralidade nos CEO surta efeito, uma vez que se houver agravamento das situações clínicas apresentadas na atenção secundária ou de média complexidade, onde se insere o CEO haverá grande demanda reprimida a nível da atenção terciária ou de alta complexidade no atendimento hospitalar. Outro 
ponto a ser considerado é o de que a maioria dos hospitais são de cunho privado, hospitais públicos são a minoria e sabe-se que dos hospitais públicos em funcionamento, poucos tem equipes odontológicas para atendimento à população.

Convém ressaltar, que a escassez de recursos é notória, tanto para a atenção secundária como para a terciária, as políticas públicas nesse sentido, primam por valorizar a prevenção em saúde bucal, evitando gerar maiores gastos futuros com agravamentos das situações de saúde (Spezzia, 2015).

Faz-se necessário estruturação da rede básica, bem como mudança no sistema assistencial vigente para que se tornem viáveis na prática os princípios de integralidade preconizados pelo SUS (Bodstein, 2002).

Os profissionais de saúde devem conscientizar-se de que a assistência à saúde deve ser compreendida como humanizada, totalizadora, contextualizada e integral, devendo por conseguinte ser considerada por profissionais de saúde e pelos gestores como meta prioritária, uma vez que concepções de práticas em saúde, advém de elaboração coletiva, considerando a motivação pessoal dos profissionais de saúde.

Atualmente ainda, a integralidade tem pouca visibilidade nas práticas de saúde. Existe avanços, no entanto, que ainda não alcançaram o patamar desejado. Mudanças no sistema de saúde, por vezes consideradas utópicas, veem a integralidade como uma realidade passível de ser alcançada. A percepção dos gestores denota que a falta de profissionais para atender a demanda age como impedimento ao alcance da integralidade, prejudicando na qualidade do atendimento prestado. Os gestores são profissionais que possuem habilidades técnicas e gerenciais, que tem como meta principal, conseguir convergir todas as prioridades entre os indivíduos que se relacionam com a empresa como colaboradores, superiores, clientes internos e externos, fornecedores internos e externos e acionistas da empresa com a sociedade como um todo. O gestor deve possuir habilidade tal que permita que esses grupos de pessoas citados, interajam com grau elevado de comprometimento e envolvimento, buscando o sucesso para todos e não o de pessoas, departamentos ou setores, individualmente (Zucchi \& Ferraz, 2009). 


\section{Conclusão}

Concluiu-se que a prática da integralidade nos CEO tende a aprimorar os atendimentos, permitindo racionalização dos recursos, evitando maiores gastos na atenção em saúde.

\section{Referências}

1 - Ministério da Saúde. Secretaria de Atenção à Saúde. Coordenação Nacional de Saúde Bucal. Diretrizes da Política Nacional de Saúde Bucal, 2004. Disponível em: http://conselho.saude.gov.br/web_comissoes/cisb/doc/politica_nacional.pdf Acessado em 21 de novembro de 2016.

2 - Viegas SMF, Penna CMM. As Dimensões da Integralidade no Cuidado em Saúde no Cotidiano da Estratégia Saúde da Família no Vale do Jequitinhonha, MG, Brasil. Interface - Comunicação, Saúde e Educação, 2015; 19(55):1089-100.

3 - Mattos RA. Os Sentidos da Integralidade: algumas reflexões acerca de valores que merecem ser defendidos. In: Pinheiro R, Mattos RA (Orgs.). Os Sentidos da Integralidade na Atenção e no Cuidado à Saúde. Rio de Janeiro: UERJ/IMS: ABRASCO, 2001, p. 39-64.

4 - Campos CEA. O desafio da integralidade segundo as perspectivas da vigilância da saúde e da saúde da família. Ciênc Saúde Coletiva 2003; 8(2):569-84.

5 - Freitas CASL, Fernandes AT, Chagas MIO, Soares CHA, Silva MJ, Brito MCC. O princípio da integralidade na perspectiva dos coordenadores de um sistema de saúde no interior do Ceará. Cad Saúde Colet, 2014; 18(4):494-9.

6 - Mattos RA. A integralidade na Prática (ou sobre a Prática da integralidade). Cad. Saúde Pública, 2004; 20(5):1411-6.

7 - Sala A, Luppi CG, Simões O, Marsiglia RG. Integralidade e Atenção Primária à Saúde: avaliação na perspectiva dos usuários de unidades de saúde do município de São Paulo. Saúde Soc, 2011; 20(4):948-60.

8 - Fracolli L, Zoboli ELP, Granja GF, Ermel RC. Conceito e prática da integralidade na 
Atenção Básica: a percepção das enfermeiras. Rev Esc Enferm USP, 2011; 45(5):1135-41.

9 - Ministério da Saúde. Secretaria de Atenção à Saúde. Secretaria de Vigilância em Saúde. Departamento de Atenção Básica. Coordenação Geral de Saúde Bucal. SB Brasil 2010: Pesquisa Nacional de Saúde Bucal: Resultados Principais. Brasília. 2011. 92.

Disponível em: http://dab.saude.gov.br/CNSB/sbbrasil/arquivos/projeto_sb2010_relatorio_final.pdf Acessado em 23 de setembro de 2015.

10 - Wade WG. Th e oral microbiome in health and disease. Pharmacol Res 2013;69(1):137-43.

11 - Brasil. Ministério da Saúde. Portaria no 599/GM de 23 de março de 2006. Define a implantação de Centros de Especialidades Odontológicas (CEO) e de Laboratório Regionais de Próteses Dentárias (LRPD) e estabelece critérios, normas e requisitos para o seu credenciamento. Brasília: Ministério da Saúde; 2006.

12 - Portaria no. 1570/GM de 29 de julho de 2004. Disponível em: http://adcon.rn.gov.br/ACERVO/Suvisa/doc/DOC000000000024937.PDF Acessado em 21 de novembro de 2016.

13 - Chaves SCL, Barros SG, Cruz DN, Figueiredo ACL, Moura BLA, Cangussu MCT. Política Nacional de Saúde Bucal: fatores associados à integralidade do cuidado. Rev Saúde Pública, 2010; 44(6): 1005-13.

14 - Lima ACS, Cabral ED, Vasconcelos MMVB. Satisfação dos Usuários Assistidos nos Centros de Especialidades Odontológicas do Município do Recife, Pernambuco, Brasil. Cad Saúde Pública, 2010; 26(5): 991-1002.

15 - Silva Jr. AG, Mascarenhas MTM. Avaliação da Atenção Básica em Saúde sob a Ótica da Integralidade: aspectos conceituais e metodológicos. In: Pinheiro R, Mattos RA. Cuidado: as Fronteiras da Integralidade. Rio de Janeiro, Abrasco, 2004. p. 241-55. 16 - Pinheiro R, Mattos RA (org). Os Sentidos da Integralidade na Atenção e no Cuidado à Saúde. 4a. ed. Rio de Janeiro, ABRASCO, 2006.

17 - Brasil. Ministério da Saúde. Secretaria de Atenção à Saúde. Departamento de Atenção Básica. Cadernos de Atenção Básica. Acolhimento à Demanda Espontânea. v. 
I, n. 28, 1a. ed, 2013. 62 págs.

18 - Spezzia S. Uma Análise das Políticas Públicas Voltadas para os Serviços de Saúde Bucal no Brasil. Rev Bras Odontol, 2015; 72(1/2): 109-13.

19 - Bodstein R. Atenção básica na agenda da saúde. CSC, 2002; 7(3):401-12.

20 - Zucchi P, Ferraz MB. Guias de Medicina Ambulatorial e Hospitalar da UNIFESP/EPM. Economia e Gestão em Saúde. 1a. ed. São Paulo: Ed. Manole, 2009, v. $1,434 \mathrm{p}$. 